\title{
Erratum: Rainfall and irrigation controls on groundwater rise and salinity risk in the Ord River irrigation area, northern Australia
}

Anthony J. Smith

Erratum to: Hydrogeology Journal (2008),

16:1159-1175

DOI 10.1007/s10040-008-0301-6

The rainfall amount for wet season 1982-1983 in Fig. 4b should be $0.72 \mathrm{~m}$ rather than $1.63 \mathrm{~m}$ as plotted. The corrected version of Fig. 4 is presented here. This error affects two rainfall values provided in the text on page 1162. In the first paragraph of the Climate section, the second sentence should read "Average annual wet-season rainfall (calculated as total annual rainfall from July to June) from 1960-1961 to 2004-2005 was 0.78 m/year...". This value is slightly less than $0.8 \mathrm{~m} / \mathrm{yr}$, which was the value stated in the original paper. The third sentence of the same paragraph should read "The maximum wet-season rainfall from 1960-1961 to 2004-2005 was $1.48 \mathrm{~m}$ in $1999-2000 \ldots$. .. Because of the error in the rainfall value reported in the paper, it was incorrectly stated that the wettest wet season was 1982-1983.

Published online: 19 December 2009

(C) Springer-Verlag 2009

The online version of the original article can be found under http:// dx.doi.org/10.1007/s10040-008-0301-6.

\section{A. J. Smith (ه)}

CSIRO Australia,

Centre for Environment and Life Sciences,

Private Bag 5, Wembley, WA 6913, Australia

e-mail: Tony.J.Smith@csiro.au

Tel.: +61-08-93336000

Fax: +61-08-93336211
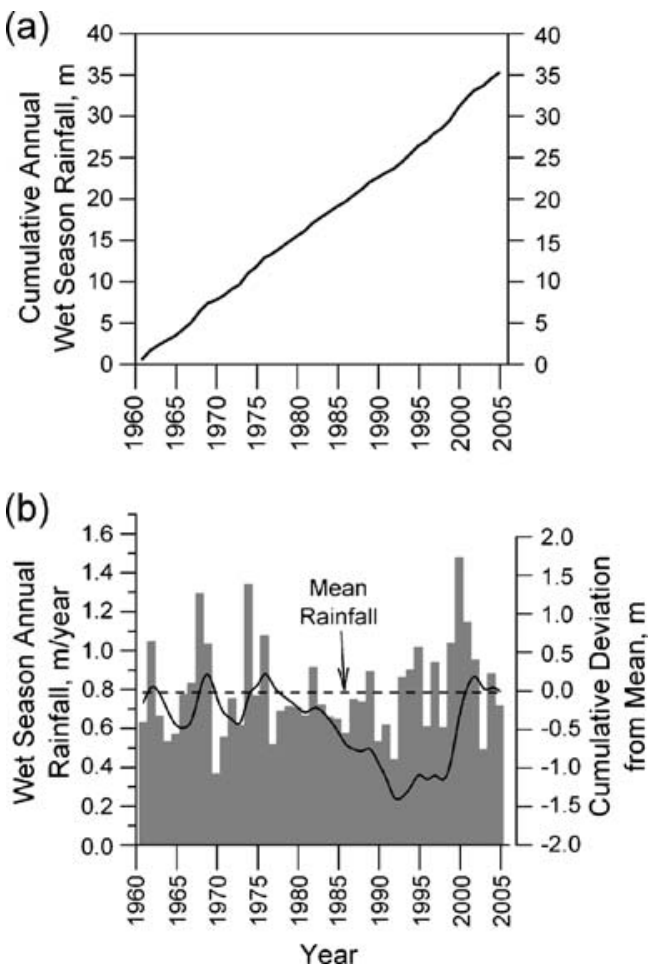

Fig. 4 Annual rainfall (wet season) at Kununurra Airport (Australian Bureau of Meteorology); (a) Cumulative annual wet season rainfall, (b) Cumulative deviation of annual rainfall from the mean (1960-61 to 2004-2005) 